\title{
DISTRIBUSI JUVENIL TUNA BERDASARKAN HASIL TANGKAPAN PURSE SEINE DI LAUT BANDA
}

\section{DISTRIBUTION OF JUVENIL TUNA BASED ON CATCED PURSE SEINE IN BANDA SEA}

\author{
Mohammad Rais ${ }^{1)^{*}}$, Eddy Hamka ${ }^{1)}$, La Ode Parisa ${ }^{1)}$ \\ ${ }^{1)}$ Program Studi Pemanfaatan Sumberdaya Perikanan Universitas Muhammadiyah Kendari
}

Diterima: 20 Oktober 2017; Disetujui: 25 April 2019

\begin{abstract}
ABSTRAK
Tuna merupakan salah salah satu jenis ikan ekonomis penting di Indonesia dan menjadi salah satu komoditas eksport utama sektor perikanan, sehingga diperlukan adanya pengelolaan yang terencana untuk menjamin keseimbangan antara pemanfaatan dan populasi tuna. Pelabuhan Perikanan Samudera (PPS) Kendari sebagai pusat pendaratan ikan menunjukkan masih banyak juvenil tuna oleh (bangkumis) tertangkap khususnya pada alat tangkap purse seine. Tujuan dari penelitan ini yaitu untuk mengetahui (1) distribusi ukuran panjang menggunakan analisis distribusi frekuensi, (2) Produktivitas penangkapan juvenil tuna yang tertangkap menggunakan analisis CPUE, (3) Sebaran spasial lokasi penangkapan juvenil tuna menggunakan analisis spasial (GIS). Penelitian dilaksanakan pada januari sampai juni 2017 di laut banda dengan Fishing base Pelabuhan Perikanan Samudera. Pengumpulan data dilakukan dengan mengikuti operasi penangkapan purse seine pada 30 Titik penangkapan lalu melakukan pencatatan ukuran panjang dan berat total tagkapan juvenil tuna. Hasil penelitian menunjukkan ukuran juvenil tuna yang tertangkap di laut banda memiliki rentang ukuran $22,5 \mathrm{~cm}-55,4 \mathrm{~cm}$. Produktivitas penangkapan dilihat dari nilai CPUE perbulan pada semua alat tangkap purse seine yang menangkap juvenil tuna di laut banda. CPUE tertinggi pada bulan juni dengan nilai $2728 \mathrm{~kg}$ per unit penangkapan dan terendah pada bulan maret dan april dengan nilai $1243 \mathrm{~kg}$ per unit penangkapan. Lokasi penangkapan juvenil tuna selama penelitian tersebar di wilayah Utara, tenggara dan selatan laut banda $\left(03^{\circ} \mathrm{LU}-06^{\circ} \mathrm{LS}, 122^{\circ} \mathrm{BT}-124^{\circ} \mathrm{BT}\right)$. Penelitian ini memberi berkontribusi dalam perumusan kebijakan pengelolaan perikanan tuna di Indonesia, khususnya di Sulawesi Tenggara, sehingga stok sumberdaya ikan tuna secara jangka panjang akan terjaga yang pada akhirnya berdampak bagi keberlanjutan ekologi dan ekonomi usaha perikanan tuna.
\end{abstract}

Kata kunci : GIS, CPUE, Produktivitas, PPS Kendari, Tuna

\begin{abstract}
Tuna is one of the most important economic fish species in Indonesia and is one of the major export commodities of the fishery sector, so there is a need for planned management to ensure a balance between the utilization and the tuna population. On Fishery Port of Kendari showed that there are still many juvenile tuna (bangkumis) caught especially in the purse seine. The objectives of this research are to know (1) the distribution of length size using frequency distribution analysis 2) the capture productivity of juvenile tuna caught using CPUE analysis, (3) spatial distribution of juvenile tuna fishing location using spatial analysis (GIS ). The study was conducted from January to June 2017 in banda sea with a fishing base of Fishery Port of Samudera. The data collection was done by following the purse seine catching operation at 30 points of catching and then recording the length and total weight of baby tuna catch. The results showed that the size of juvenile tuna caught in banda sea has a size range of $22.5 \mathrm{cmFL}-55.4 \mathrm{cmFL}$. The catching productivity is
\end{abstract}


seen from the monthly CPUE value of all purse seine catching equipment that captures juvenile tuna in banda sea. The highest CPUE is in June with a value of $2728 \mathrm{~kg}$ per capture unit and the lowest in March and April with a value of $1243 \mathrm{~kg}$ per capture unit. The location of juvenile tuna fishing in banda sea spread across the north, south and south regions of banda sea $\left(03^{\circ} \mathrm{LU}-06^{\circ} \mathrm{LS}, 122^{\circ} \mathrm{BT}-124^{\circ} \mathrm{BT}\right)$. This research contributes to the formulation of tuna fisheries management policy in Indonesia, especially in Southeast Sulawesi, so that long-term stock of tuna resources will be maintained which ultimately affects the ecological and economic sustainability of the tuna fishery business.

Keywords: GIS, CPUE, Productivity, Port of Kendari, Tuna

\begin{tabular}{ll}
\hline Contact person & $:$ Mohammad Rais \\
Email & : mohammadrais.fish@gmail.com
\end{tabular}

\section{PENDAHULUAN}

Ikan tuna tergolong dalam jenis pelagis besar yang memiliki wilayah ruaya yang luas dan merupakan komoditas perikanan ekonomis tinggi di Indonesia, sehingga sebagian besar ikan tuna yang tertangkap diarahkan untuk tujuan ekspor. Kementerian Kelautan dan Perikanan menyatakan terdapat 4 jenis ikan tuna komersial di Indonesia, yaitu Thunsus albacores (yellowfin tuna/madidihang), Thunnus obesus (big eye tuna/tuna mata besar), Thunnus macoyii (southtern bluefin tuna/tuna sirip biru selatan), Thunnus alalunga (Albacore). Perumusan kebijakan pengelolaan sumberdaya perikanan yang berkelanjutan dan bertanggung jawab, membutuhkan data dan informasi mengenai aspek biologi dan penyebaran ikan tuna, karena berkaitan erat dengan ketersediaan dan pola hidup sumberdaya ikan tuna. Penelitian dibeberapa wilayah perairan Indonesia telah banyak dilakukan, seperti Andamari et.al (2012) menunjukkan sekitar $87,5 \%$ ikan tuna sirip kuning (Thunnus albacares) yang didaratkan di Pelabuhan Benoa-Bali, didominasi jenis tuna yang masih dalam tahap perkembangan gonad. Kantun et al (2014) menjelaskan ikan tuna yang telah matang gonad banyak tertangkap pada kedalaman perairan diatas $52,5 \mathrm{~m}$ dan untuk kedalaman 30-40 m lebih banyak jenis tuna yang tertangkap masih dalam kategori belum matang gonad. Di wilayah Samudera Hindia menunjukkan status tuna mata besar (big eye) yang tertangkap sudah berumur sekitar 2 tahun dan sudah mengalami fase pemijahan, namun dari segi tingkat pemanfaatannya 
sudah mencapai status padat tangkap (Riswanto, 2012).

Chodrijah dan Nugraha (2013) menjelaskan bahwa salah satu lokasi penangkapan potensial ikan tuna di Indonesia adalah Laut Banda (WPP 714). Perairan Sulawesi Tenggara sebagai bagian dari wilayah Laut Banda memiliki potensi sumberdaya perikanan tuna yang cukup besar, menurut data statistik perikanan Pelabuhan Perikanan Samudera (PPS) Kendari antara tahun 2010 - 2014 menunjukkan produksi ikan tuna yang ditangkap di sekitar perairan Sulawesi Tenggara rata-rata 1.230 ton/tahun (PPS Kendari 2015).

Hasil pengamatan awal di PPS Kendari, diketahui masih banyak tangkapan ikan tuna tergolong juvenil tuna (8 $-12 \mathrm{~cm})$ khususnya pada alat tangkap purse seine yang oleh nelayan setempat disebut sebagai ikan "bang kumis", sementara dalam pengelolaan sumberdaya perikanan menjelaskan bahwa penangkapan ikan yang berukuran kecil akan mengancam keberlanjutan sumberdaya ikan tuna karena terkait dengan proses recruitmen sumberdaya yang tidak seimbang dengan proses pemanfaatannya. Hingga saat ini informasi mengenai tingkat penangkapan terkait jenis, ukuran, jumlah serta lokasi tertangkapnya juvenil tuna (ikan "bang kumis") di perairan Sulawesi Tenggara masih belum tersedia, sehingga diperlukan adanya penelitian ini, sebagai bahan informasi dalam upaya pengelolaan sumberdaya ikan tuna khususnya di perairan Sulawesi Tenggara agar keberlanjutan pemanfaatannya dapat terjaga, sehingga tetap memberikan manfaat ekonomi bagi nelayan serta menjamin ketersediaan pangan hewani (ikan) nasional. Tujuan penelitian ini adalah mengetahui distribusi ukuran panjang (Fork Lenght), tingkat produktivitas penangkapan dan sebaran spasial lokasi penangkapan juvenil tuna di perairan Sulawesi Tenggara.

\section{DATA DAN METODE}

Penelitian ini dilaksanakan pada bulan Januari sampai juni 2017 di Laut banda dengan fishing base yaitu Pelabuhan Perikanan Samudera (PPS) Kendari. 


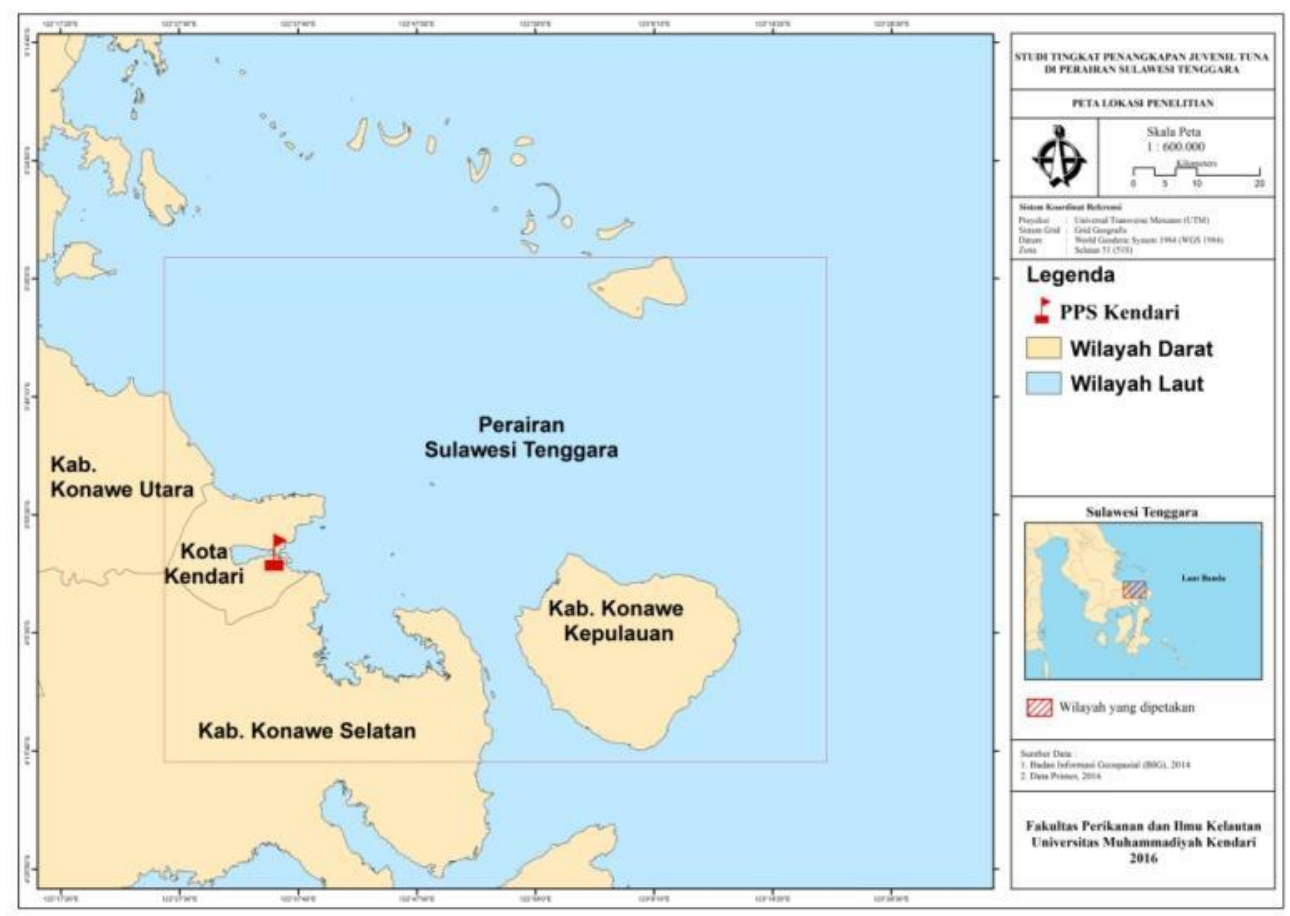

Gambar 1. Lokasi Penelitian

\section{Metode Pengambilan Data}

Penelitian ini menggunakan dua jenis data yaitu data primer dan data sekunder. Data primer adalah pengamatan langsung dilapangan dengan mengikuti operasi penangkapan purse seine meliputi data titik koordinat lokasi penangkapan dan ukuran ikan juvenil tuna yang tertangkap. Data sekunder merupakan data statistik bersumber dari Pelabuhan Perikanan Samudera Kendari meliputi data hasil tangkapan juvenil tuna bulan januari sampai juni 2017 dan jumlah armada purse seine yang beroperasi di laut banda (WPP 714) yang melakukan penangkapan juvenil tuna. Adapun rincian metode pengumpulan data sebagai berikut:

1. Data Ukuran Ikan didapatkan dengan mengukur juvenil tuna (Fork lenght) hasil tangkapan purse seine pada setiap lokasi penangkapan yang diikuti (30 Titik Lokasi penangkapan)m Masing-masing lokasi penangkapan mengukur 20 ekor juvenil tuna sebagai keterwakilan ukuran juvenil tuna setiap operasi penangkapan

2. Data produktivitas penangkapan didapatkan dari data sekunder dari PPS Kendari meliputi data hasil tangkapan juvenil tuna kapal purse seine dan jumlah armada yang melakukan penangkapan di WPP 714

3. Data lokasi penangkapan didapatkan dari perekaman titik koordinat dengan menggunakan GPS pada setiap lokasi penangkapan yang diikuti.

\section{Analisis Data}

Komposisi Ukuran

Data komposisi ukuran (panjang) ditabulasi dalam bentuk tabel, grafik dan 
histogram, lalu kemudian dianalisis secara deskriptif agar diperoleh gambaran umum mengenai kondisi penangkapan juvenil tuna pada armada purse seine di perairan Sulawesi Tenggara. Penentuan jumlah kelas ukuran (panjang dan berat), selang kelas dihitung dengan persamaan :

$K=1+3,3 \log N$

$\mathrm{K}$ : Jumlah kelas

$\mathrm{N}$ : Jumlah sampel

$P=R / K$

$P$ : Selang Kelas

$\mathrm{R}$ : Kisaran (panjang ikan tertinggi panjang ikan terendah)

$\mathrm{K}$ : Jumlah Kelas

\section{Tingkat Produktivitas Penangkapan Juvenil Tuna}

Analisis yang digunakan yaitu Catch Per Unit Effort (CPUE) dilakukan untuk mengetahui tingkat penangkapan penangkapan juvenil tuna pada alat tangkap purse seine yang beroparasi di perairan WPP 714. Data catch berupa hasil tangkapan $(\mathrm{kg})$ juvenil tuna dan data Effort (upaya) adalah trip penangkapan purse seine bulan januari sampai juni (Data sekunder). Rumus yang digunakan sebagai berikut (Sparre dan Vennema, 1999) :

4. Layout sebaran penangkapan dan informasi lainnya secara menggunakan aplikasi Quantum GIS.
CPUE $=\frac{C}{f}$

CPUE : Hasil tangkapan perunit upaya (kg/trip)

$\mathrm{C}$ : Produksi hasil tangkapan $(\mathrm{kg})$

$\mathrm{f}:$ Upaya penangkapan (trip)

\section{Pemetaan Sebaran Daerah Penangkapan}

Pemetaan lokasi tertangkapnya juvenil tuna dianalisis menggunakan aplikasi open source Quantum GIS. Titik lokasi penangkapan setiap trip penangkapan dalam format DMS (derajat, menit, second) diubah menjadi format desimal degree. Selanjutnya diimport kedalam aplikasi Quantum GIS sehingga dapat diperoleh peta sebaran lokasi tertangkapnya juvenil tuna di perairan Sulawesi Tenggara. Adapun tahapan analisis sebagai berikut :

1. Merubah titik lokasi sampel penangkapan juvenil tuna dari GPS kedalam format desimal degree beserta atribut data (jenis, ukuran, waktu dan lokasi penangkapan)

2. Membuat basis data format shapfile (SHP) dari data yang telah diolah pada langkah pertama.

3. Manipulasi tampilan SHP sehingga mudah dipahami 
Informasi komposisi ukuran juvenil tuna yang tertangkap sangat penting untuk mengkaji kondisi perikanan di perairan laut timur Sulawesi tenggara. hal ini sangat berpengaruh terhadap ketersediaan sumberdaya ikan (SDI) di perairan, karena semakin banyak juvenil tuna yang tertangkap maka ketersediaan tuna di perairan laut timur Sulawesi tenggara semakin sedikit. Adapun komposisi ukuran Juvenil tuna yang tertangkap di perairan laut timur Sulawesi tenggara dapat di lihat di bawah ini :

Tabel 3. Komposisi ukuran juvenile tuna

\begin{tabular}{|c|c|c|}
\hline $\begin{array}{c}\text { Ukuran } \\
\text { Juvenil tuna }\end{array}$ & Jumlah (ekor) & Komposisi (\%) \\
\hline $22,5-25,5$ & 9 & 1,50 \\
\hline $25,6-28,6$ & 50 & 8,33 \\
\hline $28,7-31,7$ & 87 & 14,50 \\
\hline $31,8-34,8$ & 110 & 18,33 \\
\hline $34,9-37,9$ & 86 & 14,33 \\
\hline $38,0-41,0$ & 81 & 13,50 \\
\hline $42,0-45,0$ & 105 & 17,50 \\
\hline $46,0-49,0$ & 56 & 9,33 \\
\hline $50,0-53,0$ & 8 & 1,33 \\
\hline $54,0-57,0$ & 8 & 1,33 \\
\hline \multirow[t]{9}{*}{ Jumlah } & 600 & 100,00 \\
\hline & $1 \% 2 \%$ & $22,5-25,5$ \\
\hline & & $25,6-28,6$ \\
\hline & & $28,7-31,7$ \\
\hline & & - 31,8 - 34,8 \\
\hline & & - 34,9-37,9 \\
\hline & & $38,0-41,0$ \\
\hline & & $42,0-45,0$ \\
\hline & & $46,0-49,0$ \\
\hline
\end{tabular}

Gambar 2. Komposisi Ukuran juvenil tuna selama penelitian

Komposisi ukuran juvenil tuna menunjukkan bahwa distribusi ukuran juvenil tuna yang tertangkap di Perairan Laut Timur Sulawesi Tenggara, memiliki ukuran keseluruhan dari ukuran $22,5 \mathrm{~cm}$ sampai dengan ukuran 55,4 cm, dengan jumlah masing-masing yaitu: 22,5 - 25,5 sebanyak 9 \% (9 ekor), 25,6 - 28,6 sebanyak $8 \%$ (50 ekor), 28,7 - 31,7 sebanyak $15 \%$ (87 ekor), 31,8 - 34,8 sebanyak 18 \% (110 ekor), 34,9 - 37, 9 sebanyak $18 \%$ (86 ekor), 38,0 - 41,0 sebanyak $14 \%$ (81 ekor), 42,0 - 45,0 sebanyak 18 \% (105 ekor), 46,0 - 49,0 sebanyak 9 \% (56 ekor), 50,0 - 53,0 
sebanyak $1 \%$ (8 ekor) dan 54,0 - 57,0 sebanyak $1 \%$ (8 ekor).

Dari hasil pengolahan data di peroleh jumlah distribusi ukuran juvenil tuna terbanyak berada di rentang ukuran 31,8 - 34,8 dengan jumlah 110 ekor, sedangkan rentang ukuran 50,0 - 53,0 dan 54,0 - 55,4 merupakan jumlah paling sedikit di temukan dengan masingmasing berjumlah 8 ekor. Ukuran ini merupakan juvenil tuna karena ukuran pertama kali matan gonad bagi tuna sirip kuning adalah 89,2 - 100,9 cm Mardlijah (2008) pada penelitiannya di Perairan Maluku diperoleh Lm ikan tuna sirip kuning jantan dan betina masing-masing sebesar 118,7 cm FL dan 113 cm FL. Juvenil tuna sering tertangkap di sekitar rumpon dan memiliki kepadatan yang tinggi serta berada pada lapisan kedalaman 10 - 50 meter (Josse et al. 2000) dan Priatna et al. (2010).

Distribusi tuna di perairan sangat ditentukan oleh faktor internal dari ikan itu sendiri maupun faktor eksternal dari lingkungan. Faktor internal meliputi jenis (genetis), umur dan ukuran, serta tingkah laku (behaviour).Faktor eksternal merupakan faktor lingkungan, diantara adalah parameter oseanografis seperti suhu, salinitas, densitas dan kedalaman lapisan thermoklin, arus dan sirkulasi massa air, oksigen dan kelimpahan makanan (Gunarso,1998).

\section{Produktivitas penangkapan juvenil} tuna

Purse seine yang dioperasikan di laut banda (WPP 714) merupakan alat tangkap yang memiliki tingkat pemanfaatan juvenil tuna yang paling besar. Hal ini disebabkan oleh teknik pengoperasian purse seine di sekitar rumpon. Produktivitas penangkapan juvenil ikan tuna pada bulan januari sampai juni 2017 berdasarkan data dari PPS Kendari dapat dilihat pada gambar berikut ini. 


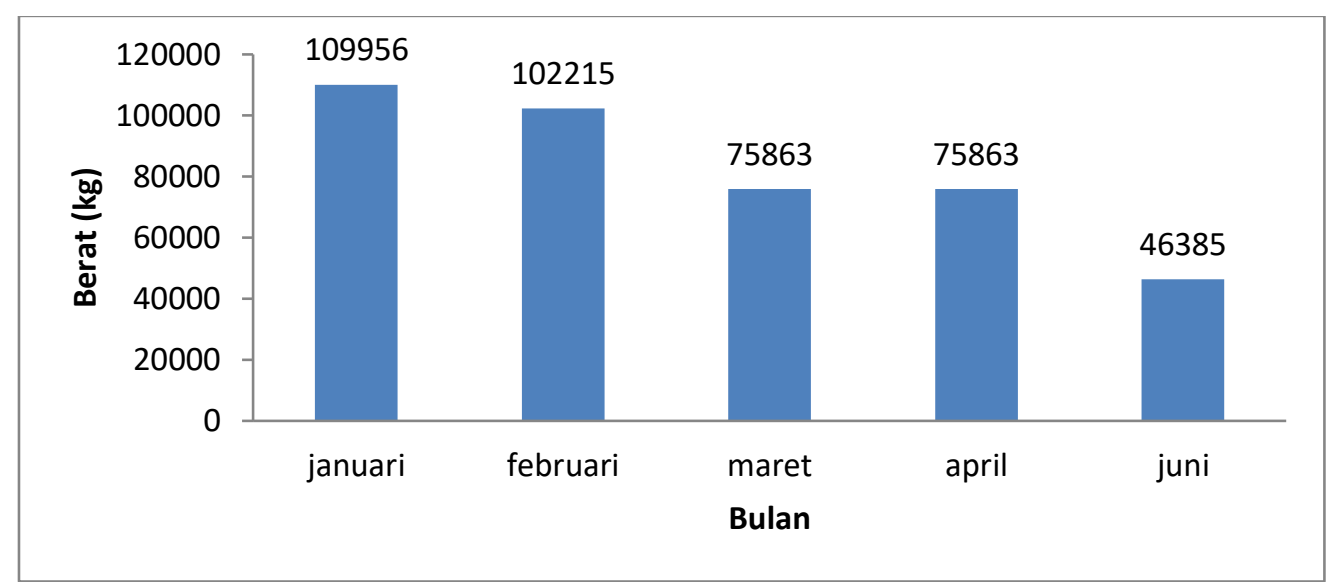

Gambar 3. Jumlah hasil tangkapan juvenil tuna periode Januari - Juni 2017 (Sumber: PPS.2017)

Hasil pengolahan data produksi hasil tangkapan juvenil tuna dalam lima bulan adalah produksi tangkapan tertinggi pada bulan januari dengan jumlah 109.956 kg dan yang terendah adalah pada bulan juni yaitu $46.385 \mathrm{~kg}$. Salah satu yang mempengaruhi produktivitas hasil tangkapan ini adalah jumlah unit penangkapan tuna yang beroperasi pada bulan tersebut. Pada bulan januari jumlah armada /unit penangkapan yang melakukan penangkapan juvenil tuna adalah 75 unit sedangkan pada bulan juni hanya sekitar 17 unit

$$
\text { Catch perunit }
$$

Effort

menggambarkan produktivitas hasil tangkapan setelah dibagi dengan unit penangkapan. Produktivitas penangkapan juvenil tuna berdasarkan CPUE selama lima bulan dapat dilihat pada gambar di bawah ini.

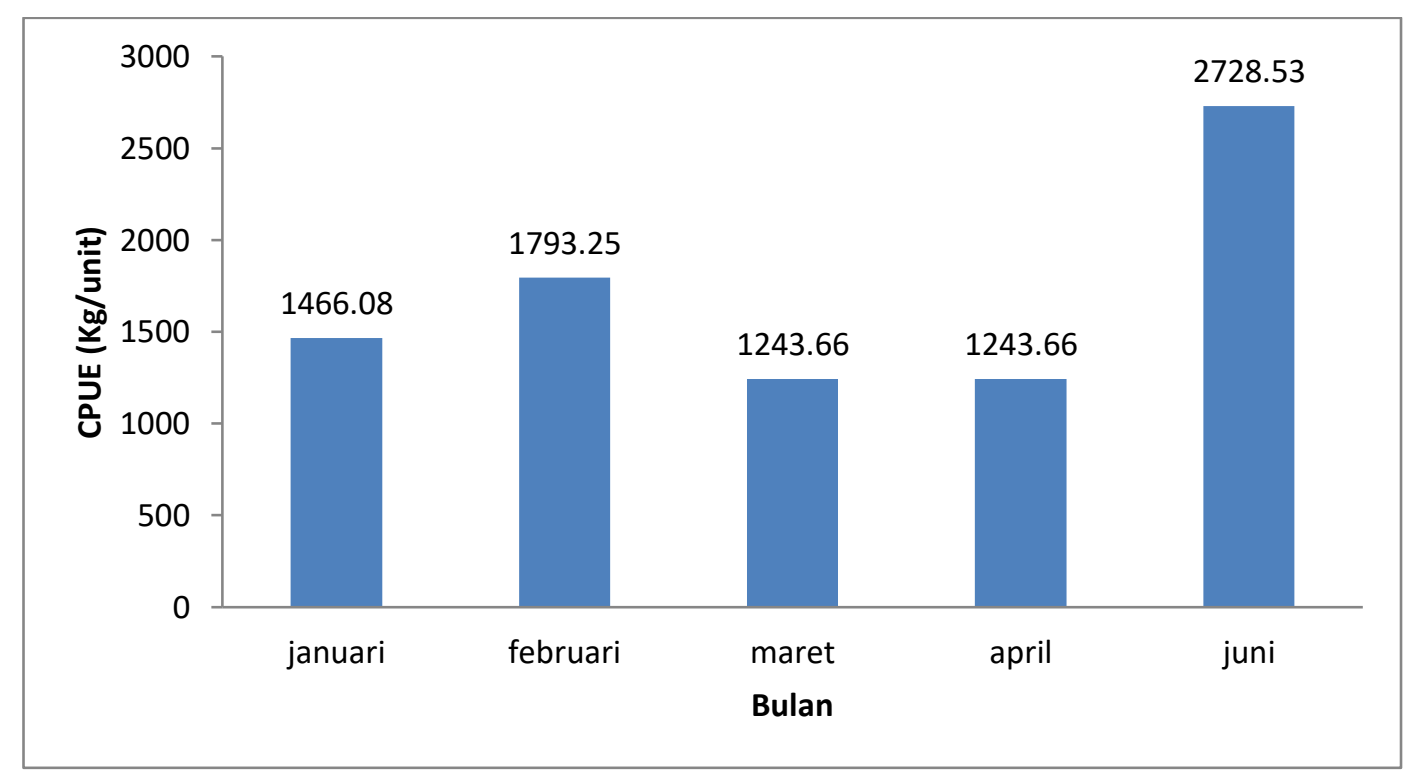


CPUE tertinggi pada bulan juni

dengan nilai $2728 \mathrm{~kg}$ atau 2 ton per unit

penangkapan. Adapun CPUE terendah

pada bulan maret dan april dengan nilai

$1243 \mathrm{~kg}$ atau 1.2 ton per unit

penangkapan.

\section{Sebaran spasial lokasi penangkapan juvenil tuna}

Perairan Sulawesi tenggara sebagai bagian dari laut banda (WPP 714) menjadi salah satu lokasi utama penangkapan ikan tuna. Alat tangkap purse seine (Pukat Cincin) yang digunakan selama penelitian adalah alat tangkap yang dioperasikan di
Perairan Laut Timur Sulawesi Tenggara dan Fishing base yang digunakan selama penelitian adalah di Pelabuhan Samudera Kendari (PPS) Kendari $\left(03^{0} 28^{\prime} 35.5^{\prime \prime}\right.$ LS dan $120^{\circ} 22^{\prime}$ 47.7" BT). Posisi fishing ground terjauh ditempuh sekitar 18 jam dengan kecepatan kapal maksimal 7-11 mil/jam. Sedangkan untuk posisi fishing ground terdekat dapat ditempuh dengan waktu 13-14 jam perjalanan. Untuk titik pengambilan data di lokasi penelitian terdapat di titik $03^{0} \mathrm{LU}-06^{\circ} \mathrm{LS}, 122^{\circ} \mathrm{BT}-$ $124^{0} \mathrm{BT}$

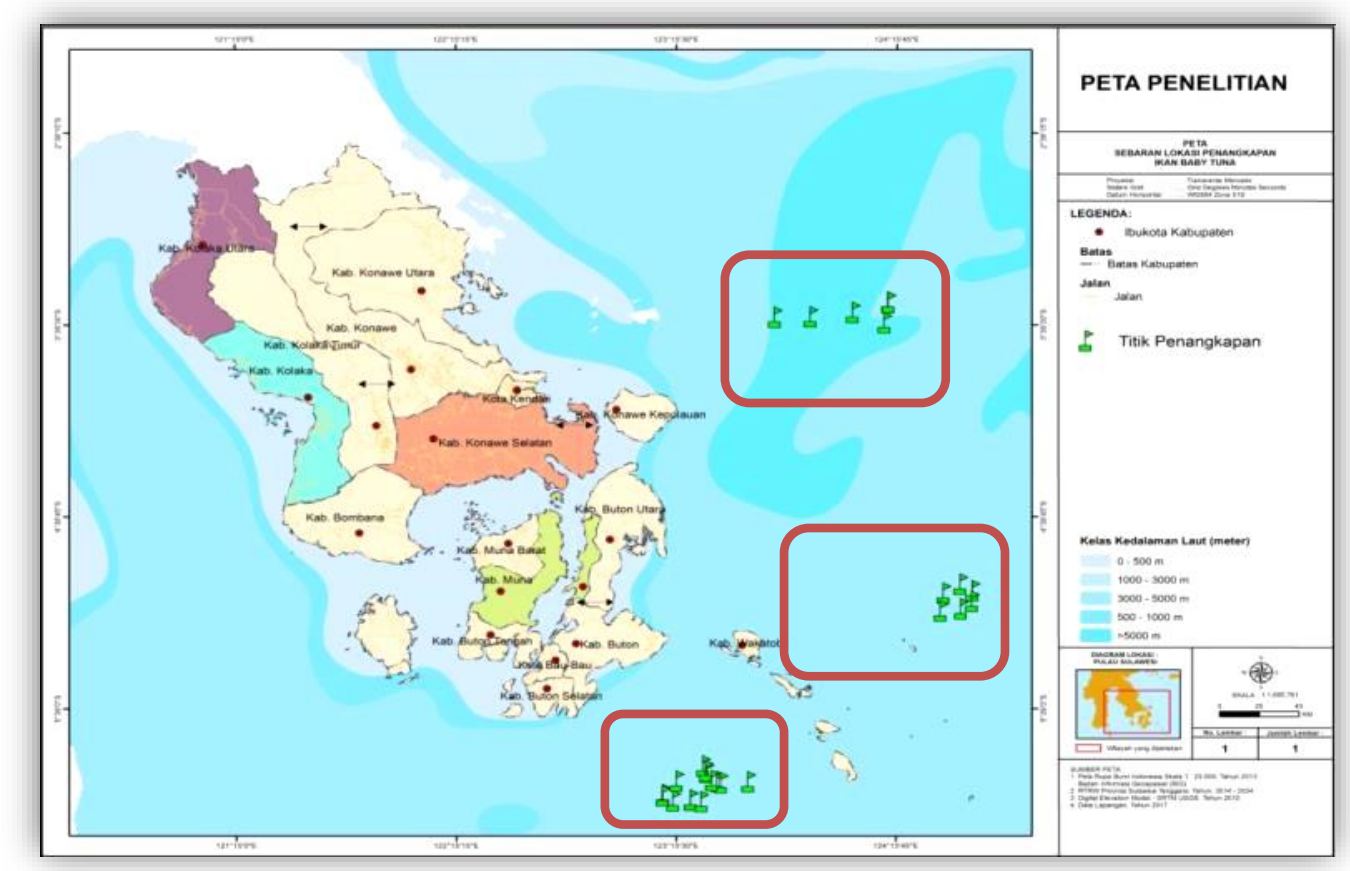

Gambar 5. Sebaran lokasi penangkapan juvenil tuna

Penangkapan tuna di perairan laut timur sulawesi tenggara dalam penelitian ini sebanyak enam kali trip penangkapan dengan jumlah setting alat tangkap sebanyak 30 kali. Sedangkan hasil tangkapan juvenil tuna dari total upaya penangkapan (trip) keseluruhan dari 216,52 kg sampai dengan 472,28 kg. Daerah penangkapan yang potensial sangat diperlukan untuk keberhasilan 
suatu operasi penangkapan. Penentuan daerah penangkapan tuna dengan tepat dapat dilakukan dengan dukungan berbagai informasi tentang daerah penangkapan serta keterangan dari nelayan yang menangkap ikan di sekitar perairan tersebut. Dalam penelitian ini, penentuan lokasi penangkapan tuna di perairan laut timur sulawesi tenggara berdasarkan pengalaman nelayan dengan cara mengamati kondisi perairan. Selain pengamatan kondisi perairan sebelum pengoperasian alat tangkap purse seine, nelayan juga menggunakan alat bantu penangkapan rumpon dan teknologi lampu celup bawah air. Pada beberapa titik penangkapan, alat bantu rumpon telah lebih dahulu di pasang agar mempermudah nelayan dalam menentukan lokasi penangkapannya tanpa harus mencari lokasi penangkapan yang memakan waktu ber jam-jam.

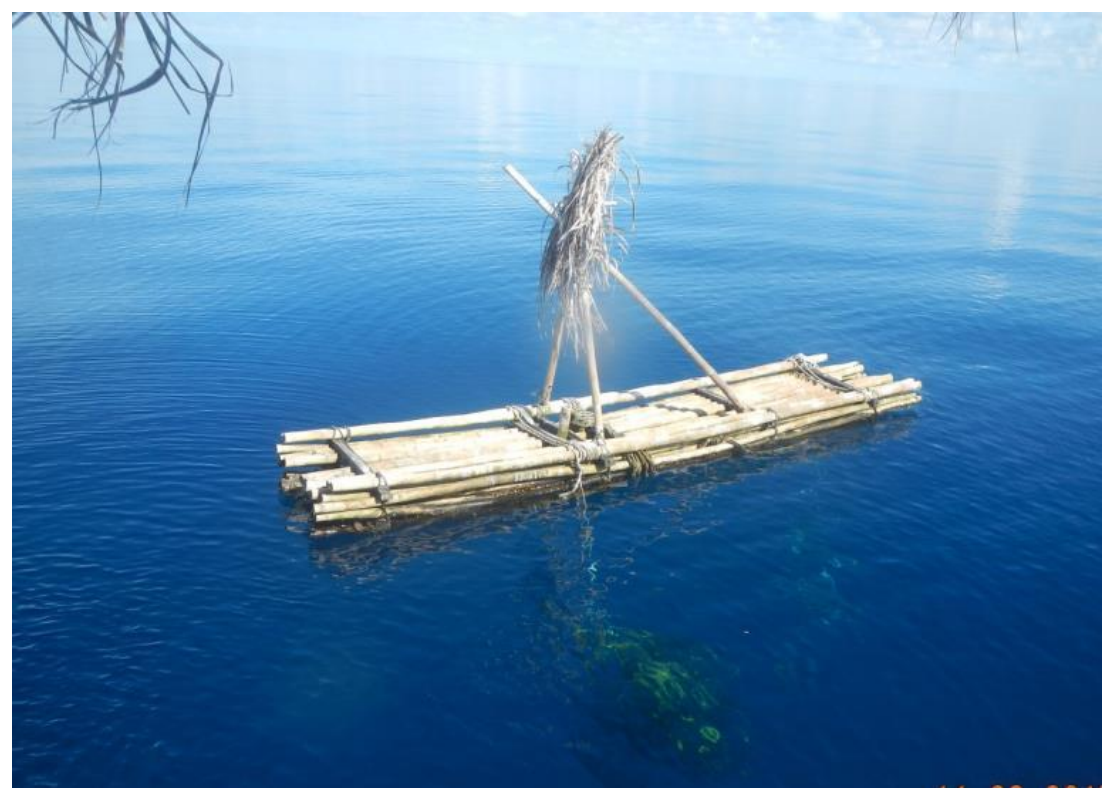

Gambar 6. Rumpon yang digunakan oleh nelayan Purse seine

Umumnya, hampir seluruh kapal purse seine telah memiliki rumpon tersendiri. Oleh karenanya, tren lokasi penangkapan kapal purse seine mengikuti pola lokasi rumpon itu dipasang. Apabila kapal purse seine telah sampai pada lokasi rumpon, maka salah seorang ABK kapal "Pakkaca" melakukan snorkling di sekitar rumpon dan melihat kondisi keberadaan ikan di sekitar rumpon. Apabila didapati gerombolan ikan maka dilakukanlah proses setting alat tangkap. Setting alat tangkap dimulai dari beberapa ABK memindahkan atraktor rumpon dari rakitnya kemudian dipasang pada kapal pembantu (sekoci). Setelah itu, sekoci di arahkan untuk berpindah menjauhi rakit rumpon agar dapat menghindari tali jangkar rumpon. Setelah atraktor rumpon dipindahkan, selanjutnya dilakukan proses pelingkaran jaring dengan melingkari atraktor rumpon tersebut.

Lokasi penangkapan selama penelitian dapat dikategori menjadi tiga kawasan yaitu daerah penangkapan yang berada di bagian utara, tenggara dan selatan dari Laut Banda (WPP 714).

1. Bagian Utara Laut banda · 123 BT - 124 BT dan 03 LS - 04 LS memanjang ke arah timur. Berada dalam perairan Menui dan sekitarnya 
2. Bagian Tenggara Laut banda - 124 BT 125 BT dan 05 LS - 06 LS terkonsentrasi pada suatu daerah membentuk lingkaran. Berada pada perairan maluku

3. Bagian Selatan Laut banda - 122 BT 123 BT dan 06 LS - 06 LS terkonsentrasi pada suatu daerah membentuk lingkaran. Berada pada perairan selatan wakatobi

\section{Kesimpulan dan Saran}

Hasil penelitian yang dilakukan di laut banda adalah sebagai berikut :

1 Ukuran juvenil tuna yang tertangkap di laut banda selama penelitian memiliki rentang ukuran rata - rata dari $22,5 \mathrm{~cm}$ sampai dengan $55,4 \mathrm{~cm}$

2 Produktivitas penangkapan dilihat dari nilai CPUE perbulan pada semua alat tangkap purse seine yang menangkap juvenil tuna di laut banda. CPUE tertinggi pada bulan juni dengan nilai $2728 \mathrm{~kg}$ per unit penangkapan. Adapun CPUE terendah pada bulan maret dan april dengan nilai $1243 \mathrm{~kg}$ atau 1.2 ton per unit penangkapan

3 Lokasi penangkapan juvenil tuna di laut banda selama penelitian dengan jumlah 30 titik penangkapan yang tersebar di wilayah Utara, tenggara dan selatan WPP $714\left(03^{\circ} \mathrm{LU}-06^{\circ} \mathrm{LS}, 122^{\circ} \mathrm{BT}-\right.$ $\left.124^{0} \mathrm{BT}\right)$.

\section{Saran}

Penelitian lanjutan sangat perlu dilakukan terutama mengenai daerah penangkapan ikan dan pengaruh arus terhadap hasil tangkapan tuna serta kelimpahan sumber daya tuna sebagai data tambahan dalam penelitian lanjutan di Perairan Laut Timur Sulawesi Tenggara

\section{DAFTAR PUSTAKA}

Andamari, R. Hutapen, J.H. Prosantoso, B.I. 2012. Aspek reproduksi ikan tuna sirip kuning (Thunnus albacares). Jurnal Ilmu dan Teknologi Kelautan Tropis. 4 (1) : $89-96$.

Chodrijah, U dan Nugraha, B. 2013. Distibusi ukuran tuna hasil tangkapan pancing longline dan daerah penangkapannya di perairan Laut Banda. Jurnal Penelitian Perikanan Indonesia. 19 (1) : 9 -16.

Josse, E., L. Dagron \&A. Bertrand. 2000. Typology and behaviour of tuna aggregation around fish aggregating device from accoustic surveys in french polynesia. Aquat Living Resour. 13:183-192.

Kantun, W. Achmar, M. dan Rapi, N.L. 2014. Struktur ukuran dan jumlah tangkapan tuna madidihang (Thunnus albacares menurut waktu penangkapan dan kedalaman di perairan Majene Selat Makassar. Jurnal Saintek Perikanan. 9 (2) : 39 - 48.

Mardlijah, S. 2008. Analisis isi lambung dan gonad ikan madidihang (Thunnus albacares Bonnatere 1788) yang tertangkap di perairan Marisa,Gorontalo, Teluk Tomini. Tesis. Fakultas MIPA, Universitas Indonesia. $105 \mathrm{p}$.

Priatna,A, D. Nugroho \&Mahiswara. 2010. Keberadaan ikan pelagis rumpon laut dalam pada musim timur di Perairan Samudera Hindia sebelah Selatan Teluk Pelabuhanratu 
Jurnal IPTEKS PSP. Vol. 6 (11) April 2019: 102-113

dengan metode hidroakustik.

Jurnal Penelitian Perikanan

Indonesia. Jakarta: Pusat Riset

Perikanan Tangkap. 16 (2): 83-91.

Riswanto, S. 2012. Status Perikanan Tuan Mata Besar (Tunnus obesus, Lowe 1839) Di Perairan Samudera Hindia, Selatan Pelabuhan Ratu, Sukabumi. Tesis. Universitas Indonesia. Depok.
Pelabuhan Perikanan Samudera Kendari. 2015. Data Statistik Perikanan PPS Kendari tahun 2010 - 2012. Kendari.

Sparre, P. Vennema, S.C. 1999. Introduksi Pengkajian Stok Ikan Tropis. Edisi 1. FAO dan Pusat Penelitian dan Pengembangan Perikanan. Badan Penelitian dan Pengembangan Pertanian. Jakarta. 